Abstracta Iranica Iranica

Revue bibliographique pour le domaine irano-aryen

Volume 29 | 2008

Comptes rendus des publications de 2006

\title{
Multi-ethnic Empires and the formulation of identity. Routledge-Taylor \& Francis Ltd, 2003, pp. 70-101.
}

\section{Camille Rhoné}

\section{(2) OpenEdition \\ 12 Journals}

Édition électronique

URL : http://journals.openedition.org/abstractairanica/27332

DOI : 10.4000/abstractairanica.27332

ISSN : 1961-960X

\section{Éditeur :}

CNRS (UMR 7528 Mondes iraniens et indiens), Éditions de l'IFRI

\section{Édition imprimée}

Date de publication : 15 mai 2008

ISSN : 0240-8910

\section{Référence électronique}

Camille Rhoné, « Multi-ethnic Empires and the formulation of identity. Routledge-Taylor \& Francis Ltd, 2003, pp. 70-101. », Abstracta Iranica [En ligne], Volume 29 | 2008, document 139, mis en ligne le 15 septembre 2008, consulté le 26 septembre 2020. URL : http://journals.openedition.org/ abstractairanica/27332 ; DOI : https://doi.org/10.4000/abstractairanica.27332

Ce document a été généré automatiquement le 26 septembre 2020.

Tous droits réservés 


\title{
Multi-ethnic Empires and the formulation of identity. Routledge- Taylor \& Francis Ltd, 2003, pp. 70-101.
}

\author{
Camille Rhoné
}

1 Beatrice Manz s'intéresse aux relations entre identité et empire à l'époque prémoderne et hors d'Europe, tout en démontrant que les groupes identitaires peuvent survivre aux structures impériales. Elle dégage ainsi divers modèles : l'empire austrohongrois tout d'abord, qui a servi, à tort, de modèle pour les érudits occidentaux ; or dans ce cadre impérial, les identités se forgent surtout à partir de lois, de coutumes, d'une histoire et d'une langue communes. Ces critères sont ceux qu'a imposés le nationalisme européen du XIX ${ }^{\mathrm{e}}$ siècle.

Or il existe un autre modèle : celui de l'Empire islamique califal puis de l'Empire mongol. Dans ce cas, c'est le mode de vie - nomade ou non - qui est primordial, tandis que la religion et la langue sont secondaires; la légitimité politique n'est pas basée sur une logique territoriale. Le pouvoir repose sur un système double : d'une part, des dirigeants, souvent allogènes et nomades, qui cultivent leur différence identitaire par rapport à leurs sujets ; d'autre part, des populations sujettes, sédentaires, qui fournissent à la fois le personnel administratif et la langue de la haute culture. Cette population est habituée à des souverains extérieurs, dont elle attend une protection fiable, notamment grâce à l'armée de plus en plus composée d'éléments türks. Les dirigeants - califes d'origine arabe, puis Turco-Mongols descendants des gengiskhanides - ont des prétentions universalistes, entendent conserver un pouvoir considéré comme dynastique et, dans les territoires musulmans, se prétendent protecteurs de l'islam. $A u X^{e}$ s., au sein de l'Empire mongol, émergent de nouvelles identités, basées sur des conceptions divergentes du pouvoir, le critère identitaire essentiel étant désormais l'allégeance politique. Dès lors, la construction d'identités différentes se base sur deux conceptions du pouvoir : d'une part, les élites hésitent 
entre la séparation ou l'assimilation avec les populations sujettes ; d'autre part, entre état centralisé ou pouvoir dispersé.

3 L'Empire russe puis soviétique établit ensuite un pont, temporel, géographique et idéologique, entre les deux conceptions de l'empire multi-ethnique et des identités qui le composent : d'une part, il conserve le principe ségrégatif entre dirigeants et population, et entérine certaines réalités identitaires antérieures lors de la formation des républiques d'Asie centrale ; d'autre part il forge des identités selon les critères du nationalisme inspiré de l'Empire austro-hongrois.

INDEX

Thèmes : 4.0. Généralités

\section{AUTEURS}

CAMILLE RHONÉ

Paris 